\title{
Spinoza, Nietzsche y la creación de valores
}

Homero Santiago Universidad de Sao Paulo, Brasil

\section{Abstract}

Spinoza and Nietzsche have promoted a critical analysis of the current morality; both rose to discover the untruth of the conception of transcendent values. For Nietzsche, such discovery leads him to determine the creation of values as an imperative task of the new philosophers. Could the same be applied to Spinoza? In the Spinozism, could we not find something similar to a need for creation of values? We have tried to answer these questions mainly analyzing the beginning of $O n$ the improvement of the understanding.

Keywords: Spinoza, Nietzsche, values, morality, good and evil.

\section{Resumen}

Tanto Spinoza como Nietzsche promueven un análisis crítico de la moral vigente; ambos terminan descubriendo la falsedad de la concepción de valores trascendentes. En el caso particular de Nietzsche, tal operación lo conduce a determinar la creación de valores como una tarea imperativa para los nuevos filósofos. ¿Lo mismo podría ser dicho de Spinoza? ¿No encontraríamos en el spinozismo algo que se aproximaría a una necesidad de crear valores? Intentamos contestar a tales cuestiones mediante un análisis del inicio del Tratado de la reforma del entendimiento.

Palabras clave: Spinoza, Nietzsche, valores, moralidad, bien y mal. 
Wietzsche, como se sabe, en cierto momento de la vida llegó a 1 ver a Spinoza como un predecesor. En una célebre carta del 30 de julio de 1881, exclama: "tengo un predecesor iy qué predecesor!", dando una medida de cuánto se identificaba con ese pensador holandés que era "el más inaudito y más solitario" y, por eso mismo, "el más cercano" de él. Aunque varios otros textos y pasajes nietzscheanos critiquen a Spinoza, son innegables algunos puntos de gran proximidad $;^{1}$ el mismo filósofo alemán enumera algunos: hacer del conocimiento el más potente de los afectos, negar el libre arbitrio, la teleología y las causas finales, el orden moral del mundo, el mal. ${ }^{2}$

Siguiendo en esa dirección, nuestro propósito es sugerir una congruencia más entre Spinoza y Nietzsche en lo que se refiere a un tópico específico que es la tarea de crear valores. Es un tema por excelencia nietzscheano, por supuesto, y Spinoza está lejos de formular explícitamente algo del género; pensamos, sin embargo, que es posible establecer cierto paralelo entre algunas de las exigencias y

${ }^{1}$ Para una consideración de la totalidad de los textos nietzscheanos sobre Spinoza, puede verse el trabajo de Giuseppe Turco Liveri (2003).

2 "No es sólo que su tendencia general — de convertir al conocimiento en el más poderoso de los impulsos - sea igual a la mía; me identifico con cinco puntos principales de su doctrina: éste, el más inaudito y más solitario de los pensadores es el más cercano a mí precisamente en esas cosas: niega el libre arbitrio, las finalidades, el orden cósmico-moral, lo no egoísta, lo malo; si seguramente también las diferencias son enormes, eso se debe más a la diversidad de época, de cultura, de ciencia" (Nietzsche, 1986).

Por comodidad, las citas de Spinoza y de Nietzsche serán referidas por la división interna de cada obra (generalmente párrafos); las traducciones siempre fueron cotejadas con los originales y a veces modificadas. En el caso de Nietzsche, siempre que sea posible, nos servimos de las traducciones (de diversos traductores) ofrecidas en el sitio Nietzsche en castellano. 
expectativas que conducen a Nietzsche a determinar la creación de los valores como tarea propia del filósofo del porvenir y ciertos pasos de la filosofía spinoziana; convergencia que se da menos al nivel de las tesis que en el tipo de respuesta a algunas cuestiones.

La muerte de Dios, para Nietzsche, es "el mayor de los acontecimientos" de su época, y con eso asistimos al ascenso del nihilismo, o sea: "falta la finalidad; falta la respuesta al ¿para qué? ¿Qué significa el nihilismo? -que los valores supremos se desvalorizan-" (Nietzsche, 1999 frag. 9[35]). La contemporaneidad entre los dos eventos se explica con facilidad. Dios siempre fue el garante de nuestros valores, de nuestra moral; desde que tal figura sale de escena, los valores y la moral se tambalean y terminan siendo desacreditados. Así, desaparecen del horizonte o pasan al rol de meras fabulaciones todas las viejas certezas que servían para tranquilizar la existencia, particularmente los fines y los objetivos, los "para qué".

Habrá, sin embargo, dos formas de encarar ese nihilismo y, por lo tanto, la muerte de Dios: pasiva o activamente, como explica la secuencia del fragmento póstumo citado. Por un lado, el nihilismo puede determinar sólo un "ocaso y regresión del poder del espíritu"; nihilismo pasivo que no verá más que la ausencia de fines, valores y "para qué", y en ello se detendrá. Por otro lado, el nihilismo puede asumir una forma activa, siendo señal de una potencia aumentada, "signo de fortaleza" de un espíritu que, en vez de lamentar la muerte de los fines y los valores, percibe que le eran inadecuados y ve ahí una liberación, verdadera iluminación de nuevas posibilidades (frag. 9[35]).

Tal panorama configurado por la muerte de Dios y el nihilismo es determinante para el filosofar nietzscheano, en la medida en la que establece nuevas cuestiones, nuevas exigencias y, en no menor 
medida, nuevas perspectivas; en particular, al filósofo que acata la orientación de la época (Dios está muerto) cabrá el cumplimiento de una exigencia - la crítica de los valores - y de ese modo la apertura de una perspectiva -la creación de nuevos valores.

"Necesitamos una crítica de los valores morales", dirá la Genealogía de la moral (prólogo, \$6). Como explica el filósofo, "en un primer momento" la cuestión puede parecer "un asunto aislado"; sin embargo, ya no se trata solamente de poner bajo sospecha los valores, será menester ir más allá. En contestación a una "nueva exigencia", la crítica será menos condena que comprensión, y es en los meandros de ese esfuerzo comprensivo que surgirá el carácter inédito de la iniciativa. "Necesitamos una crítica de los valores morales", dijimos citando la Genealogía; ahora completemos: "hay que poner alguna vez en entredicho el valor mismo de esos valores”. Subrayemos esa idea clave, bajo la cual está buena parte de la novedad que el propio Nietzsche se atribuye: indagar por el valor de los valores. ¿Qué es un valor? Más o menos, todos lo sabemos; sabemos que tenemos valores y cuál es el papel de ellos: organizan la vida y el mundo. Lo que es necesario descubrir es que todo valor tiene un origen, una historia, pero que su génesis muchas veces es olvidada posibilitando el pasaje de un valor, desde una situación particular, como perspectiva de un ser, a un sitio trascendente. Así se levantan valores como bien y mal, que no expresan más ninguna perspectiva, sino que valoran todo $y$ a todos, no siendo sin embargo, ellos mismos, valorados; en efecto, uno de los rasgos de la institución de una moral es el olvido del proceso de formación de los valores y su surgimiento como valores desde siempre existentes y, más allá de toda determinación o producción humana, impuestos al mundo y a los hombres.

Ahí entrará toda la genialidad nietzscheana, su originalidad, al poner en funcionamiento una genealogía e investigar cuáles son las condiciones y circunstancias del nacimiento de un valor, cuál es su 
desarrollo, sus modificaciones, etc.; arte histórico que toma los valores no como entes naturales o determinaciones divinas, sino como productos humanos dotados de una historia. Es una de las posibilidades inmediatamente abiertas por la emergencia del nihilismo, la posibilidad de evaluar los valores. ¿Cómo hacerlo? Quien habla de evaluación habla de una medida evaluadora, por lo tanto, de un valor que valora el objeto que está en evaluación; pero desde que los propios valores deben ser evaluados, ¿cuál podrá ser el eje de la balanza nietzscheana? Los valores son interpretaciones, no corresponden a ninguna cosa en el mundo y, por lo tanto, no se dejan evaluar por la medida tradicional de lo verdadero y de lo falso; por el contrario, verdadero y falso son también valores y para no incurrir en petición de principio el genealogista debe renunciar a esa medida fácil. La novedad de su ejercicio exigirá un nuevo fiel, más objetivo: la vida. Todos los valores deberán ser evaluados por este valor fundamental y juzgados según favorezcan o obstaculicen la vida. En la Genealogía, en efecto, Nietzsche describe así su "problema":

¿En qué condiciones se inventó el hombre esos juicios de valor que son las palabras bueno y malo?, ¿y qué valor tienen ellos mismos? ¿Han frenado o han estimulado hasta ahora el desarrollo humano? ¿Son un signo de indigencia, de empobrecimiento, de degeneración de la vida? ¿ $\mathrm{O}$, por el contrario, en ellos se manifiestan la plenitud, la fuerza, la voluntad de la vida, su valor, su confianza, su futuro? (prólogo, \$3).

Idea seminal que una anotación de la misma época condensa en estos términos: “¿Cómo medir objetivamente el valor? Solamente por el quántum de potencia intensificada y organizada" (Nietzsche, 1999: frag. $11[83])$.

He aquí que la cuestión de los valores, la nueva exigencia de una crítica de los valores, nos remite no sólo al pasado sino también al futuro. El trabajo histórico-crítico de comprensión y evaluación de los valores es la precondición de la tarea final que se impone a los filó- 
sofos con la muerte de Dios. Como explica en Más allá del bien y del mal, dicha crítica "quiere algo distinto"; y este "algo distinto" no es sino la exigencia de crear valores, superando el nihilismo por medio de la institución de un nuevo mundo:

Los auténticos filósofos son hombres que dan órdenes y legislan: dicen “¡así debe ser!", son ellos los que determinan el "hacia dónde" y el "para qué" del ser humano, [...] ellos extienden su mano creadora hacia el futuro, y todo lo que es y ha sido conviértese para ellos en medio, en instrumento, en martillo (Nietzsche, 1985: \$211).

Crear valores, ¿pero cuáles? La medida de la vida constituye el fondo de una respuesta, sin embargo, indeterminada. No sabemos cuáles valores se crearán, aunque serán ciertamente valores a ser medidos por su poder de favorecer la vida, organizar e intensificar la potencia del viviente. Desde que Dios murió, los valores son interpretaciones, creaciones; entonces, ¿por qué no crear otros nuevos, o incluso rescatar algunos, renovándolos, con tal de que favorezcan la vida (organicen e intensifiquen la potencia) en vez de estorbarla o renegarla (intensificando la tristeza)? Esos nuevos valores, quizá, puedan darle forma a una nueva moral; sin embargo - y éste es un punto importante- ha de ser una moral de los afectos alegres, fortificantes de nuestro ser; que no vaya a buscar lastre y razones detrás de las estrellas, sino que (según el dicho de Zaratustra, prólogo, \$4) se consagre a la tierra, diciéndole sí a la vida.

Es desde ese cuadro sumario de un movimiento propiamente nietzscheano que nos gustaría tratar de Spinoza y, específicamente, de la cuestión de la creación de valores en el spinozismo.

Tanto Spinoza como Nietzsche se esfuerzan en un análisis crítico de la moral y de los valores; ambos terminan descubriendo la falsedad de la concepción de valores trascendentes y, de esa manera, determinando la inexistencia de un orden moral del mundo; por esta vía, 
finalmente, ambos se refieren a una situación de "nihilismo", quiere decir, el resultado de sus análisis nos instalan en un mundo en el que los valores tradicionales se desvalorizaron. En el caso de Spinoza, la afirmación exige, por supuesto, explicaciones. Es evidente que él no utiliza el término "nihilismo" (y ni podría hacerlo, dado que, si no nos engañamos, la palabra ni siquiera existía en su época); es el caso de preguntar, sin embargo, si la crítica spinoziana a la moral no nos coloca en una situación, en un estado de espíritu muy próximo al nihilismo ochocentista. Pensemos, por ejemplo, en la parte I de la Ética, en especial en su apéndice, el más duro de los textos spinozianos contra el finalismo y los valores. Es desde el finalismo que se originan nuestros valores o prejuicios sobre "el bien y el mal, el mérito y el pecado, la alabanza y el vituperio, el orden y la confusión, la belleza y la fealdad, y otros de este género" (Spinoza, 1987: 90); nociones que nada dicen de lo real, sino que "son sólo modos de imaginar". Bueno, ¿con qué se topa el lector? Con la ausencia de sentido provocada por la desvalorización de los valores trascendentes y, de modo general, por la supresión de cualquier más allá.

La sensación de letargo que puede tomar ese lector no es injustificada ni un puro ceder a una especie de nostalgia del prejuicio. Antes bien, es expresión sincera de un hecho: la sustancia spinoziana no nos ofrece, al menos en el apéndice, un mundo más auspicioso que el mundo sin Dios. Todo es necesario y determinado; no hay libre albedrío ni causas finales; los seres reales son singulares y los universales no tienen realidad; nuestros valores no son sino nociones que los hombres forjan y aplican a las cosas. Estamos frente a un mundo yermo, desnudado de cualquier trazo humano, y que es y acontece más allá de cualquier relación con el hombre; nuestras categorías y valores simplemente nada expresan de real y son siempre relativas, es decir, son una valoración de las cosas que surge según el modo en que cada cosa afecta a cada hombre según la constitución de ese hombre. Un mundo en el que, como en Nietzsche, no hay ni fines ni "para qué". 
Ahora, en Nietzsche, como hemos observado, la superación del nihilismo es posible prioritariamente por la creación de nuevos valores desde otras bases distintas de la trascendencia. En ese caso, nuestra cuestión es: ¿lo mismo sucedería en el spinozismo? Más precisamente: ¿el filósofo spinoziano que promueve un análisis de los valores y alcanza una situación que puede ser llamada de "nihilismo" necesitará también, en un segundo momento, crear o forjar valores nuevos? Después de la crítica a la moral, ¿Spinoza llegará a dar un paso semejante al de Nietzsche?

Creemos que es posible dar una respuesta afirmativa. El filósofo spinoziano tendrá como tarea, una vez realizado el análisis crítico de los prejuicios y de la moral, la creación o institución (para usar un término más próximo al universo spinoziano) de nuevos valores que favorezcan la vida, esto es, favorezcan los encuentros alegres y nos afirmen en la búsqueda de la felicidad, que proporcionen el aumento de nuestra potencia. Aun cuando sean poco importantes desde la perspectiva de la realidad sustancial, los valores tendrán un papel relevante a cumplir en la constitución de un mundo humano, por lo tanto, en el plano de la realidad modal. Es por esa vía que nos parece que pueden ser leídos algunos pasajes spinozianos muy curiosos en que, no obstante la tenaz denuncia del finalismo y de la irrealidad de nuestros valores, Spinoza procede a una recuperación de lo que llama "modelos" (exemplares), de los fines y de los valores. Uno de los casos más notorios es el de la Ética IV, cuyo prefacio — sin dejar de afirmar la irrealidad de los valores y de los modelos universales - propone la reconquista de las nociones de fin, bueno y malo que habían sido expulsadas del terreno filosófico. En un corto pasaje de texto, se concentran la crítica y el rescate de lo que es criticado. ¿Por qué retomar tales nociones después de su destrucción? ¿Con qué derecho?

Abandonando la Ética, nuestra intención es investigar tales cuestiones y justificar nuestro punto de vista a partir del análisis de ciertas líneas maestras de un texto en el que el filósofo, puesto en una situa- 
ción semejante a las descritas en la Ética I y IV, realiza un movimiento que, nos parece, se aproxima mucho a una creación de valores. Un texto significativamente bello que relata el inicio del filosofar spinoziano, colocando a la institución de nuevos valores como un puente entre un pasado de decepción y la promesa de una vida mejor: el Tratado de la reforma del entendimiento.

Obra de juventud e inacabada, el Tratado de la reforma del entendimiento expone en sus primeros párrafos la narrativa de una conversión a la filosofía. La secuencia es bastante conocida (estando entre las páginas más célebres del spinozismo) y, hasta cierto punto, es previsible en sus componentes: la primera persona del singular, la decepción con la vida común y lo que ella propone como felicidad; incertidumbres, la decisión de indagar por un bien verdadero, y así sucesivamente.

Después que la experiencia me había enseñado que todas las cosas que suceden con frecuencia en la vida común son vanas y fútiles, como veía que todas aquellas que eran para mí causa y objeto de temor, no contenían en sí mismas ni bien ni mal alguno a no ser en cuanto que mi ánimo era afectado por ellas, me decidí (constitui), finalmente, a indagar si existía algo que fuera un bien verdadero y capaz de comunicarse, y de tal naturaleza que, por sí solo, rechazados todos los demás, afectara al ánimo; más aún, si existiría algo que, hallado y poseído, me hiciera gozar eternamente de una alegría continua y suprema (Spinoza, 1988: $\$ 1$ ). ${ }^{3}$

\footnotetext{
${ }^{3}$ Es natural que este texto, redactado en la primera persona del singular, motive la cuestión acerca de su tenor autobiográfico; por eso es bueno, desde luego, advertir que no nos ocuparemos de ese punto controvertido (y que creemos sin solución conclusiva). El lector podrá identificar allí, según prefiera, a Spinoza, a otra persona o a un personaje ficticio.
} 
Desde ese párrafo de apertura, podemos discernir tres momentos estructuradores de la narrativa que orientarán nuestro análisis; son tres etapas del trayecto spinoziano que lleva de la vida común al filosofar: 1) "después que la experiencia me había enseñado". Hubo una enseñanza de la experiencia, tal enseñanza tiene un "después”, por lo tanto debe tener un “antes”. ¿Cuál es el antes, cuál es la enseñanza? ¿Cómo se dan las condiciones de posibilidad de la indagación por un bien verdadero? 2) "Me decidí, finalmente, a indagar". Entre la enseñanza de la experiencia y la toma de la decisión hay un tiempo, un intervalo (del "después" hasta el "finalmente"), que es aquel del decidirse. 3) Una vez decidido a indagar por un bien verdadero, el filósofo busca y determina tal bien; éste es descubierto, aunque no haya sido adquirido. Es lo que permitirá el establecimiento de un fin que determinará la vía a ser seguida.

¿Qué es lo que le permite a una persona preguntarse por un bien verdadero? Fundamentalmente, la desconfianza de que los bienes (y también los males) que le fueron propuestos sean falsos o, por lo menos, inciertos. Al enseñarnos el vacío existente detrás de las ideas de bien y mal, que "sólo se dicen en sentido relativo" (\$12), la experiencia nos lleva a sospechar de la escala de valores de la "vida común", poniendo en suspenso las certezas que ésta provee. En ese sentido, estamos frente a una experiencia de la desconfianza.

Ese primer rasgo de la experiencia nos conduce a otro, quizá más primordial: en efecto, hablamos de una experiencia de la decepción. Los bienes de la vida común, cuando nos son presentados, envuelven una promesa y nos proponen un pacto: si accedemos a ellos, nos darán algo. Pero, como sabemos por el Tratado, la certeza de la vanidad y futilidad de lo que ocurre en la vida común se debe a la experiencia de que tal vida no cumple sus promesas; o sea, sus bienes se vuelven inciertos porque de ellos desconfiamos, y de ellos desconfiamos porque se mostraron decepcionantes. 
Decepción y desconfianza — articulados, esos elementos dan forma a un tipo específico de experiencia que, al estremecer el sistema de la vida común en el que estamos insertos, abre un campo de nuevas posibilidades- Pero, ¿cómo dicha experiencia puede estremecer el sistema de la vida común? ¿Cómo llegar a sospechar de aquello que siempre fue dado como verdad cierta e incuestionable? Un breve excurso por el apéndice de la primera parte de la Ética puede resultar aquí esclarecedor.

El objetivo del apéndice es denunciar los prejuicios que impiden la comprensión de la primera parte de la Ética, el "De Dios". El texto, sin embargo, no se detiene en el tratamiento de los diferentes prejuicios; la estrategia de Spinoza es el análisis detallado de un "único" prejuicio, aquel al cual se reducen los demás y que podemos denominar prejuicio finalista. ${ }^{4}$ Será menester comprender la génesis de tal prejuicio y cómo se transforma en superstición.

Para ello, Spinoza parte de un dato fundamental y universal que remite a la condición humana: "todos los hombres nacen ignorantes de las causas de las cosas y todos los hombres poseen el apetito de buscar lo que les es útil, y de ello son conscientes". La secuencia es un trayecto deductivo cerrado, mostrando cómo a partir de su situación originaria los hombres llegan, desde luego, al prejuicio y de éste pasan a la superstición. Es un aspecto genial del texto: asistimos a la génesis de un sistema, una estructura (Spinoza usa la palabra latina fabrica) que es también un sistema de vida dotado de valores, deberes y penas para los hombres, y de explicaciones acerca del mundo, de su origen, su funcionamiento y su fin.

4 "El hecho de que los hombres supongan, comúnmente, que todas las cosas de la naturaleza actúan, al igual que ellos mismos, por razón de un fin, e incluso tienen por cierto que Dios mismo dirige todas las cosas hacia un cierto fin, pues dicen que Dios ha hecho todas las cosas con vistas al hombre, y ha creado al hombre para que le rinda culto". Aquí, como hasta el fin del análisis del apéndice de la Ética, todas las citas sin indicación provienen de este texto. 
Todo eso ocurre con tal naturalidad y necesidad desde la condición originaria de los hombres que nos queda la impresión de que nunca se podría escapar de tal estructura, a no ser por un milagro. Todos los hombres, resaltemos la asertiva de Spinoza, "son por naturaleza propensos a abrazar el prejuicio"; en esa medida, huir de la superstición sería un poco como ir contra la naturaleza. Desde que la superstición se instala, parece volverse un destino, una fatalidad. No obstante, acompańando los desdoblamientos del apéndice, descubrimos que el filósofo no deja de sugerir que sí hay posibilidad de escapar del sistema de la vida finalista. Y eso es posible, por así decir, desde adentro; no por la intervención de la razón o de la matemática (cuya "norma de verdad" será loada en el mismo apéndice), sino por la propia experiencia de vida. Es un punto que merece toda nuestra atención.

Estamos en el corazón del finalismo. Es decir: se concluyó que el mundo fue creado por un Dios que dispuso todo en beneficio de los hombres a fin de que estos le prestasen honores, culto y obediencia. Este es nuestro deber, y de allí resulta una especie de código: quien loa y obedece al dirigente de la naturaleza es beneficiado, caso contrario, es castigado; a más culto y obediencia, más beneficios; a menos culto y obediencia, más castigos. Ahora bien, los hombres podrían ser felices siguiendo tales prescripciones, si no fuese por el hecho desgraciado de que el mundo insiste en contradecir las certezas propuestas por el finalismo. "Os ruego consideréis en qué ha parado el asunto", exclama Spinoza, "la naturaleza y los dioses deliran". El delirio es la demostración cotidiana de que los males están por todas partes y alcanzan indistintamente a los impíos y a los hombres más piadosos; además, de que los bienes son acumulados por los más impíos y los más viles entre los hombres. En suma, todos los días la experiencia sugiere la incoherencia del finalismo y de sus explicaciones para el mundo; cada día, va a afirmar el filósofo, la experiencia protesta. 
Y aunque la experiencia protestase cada día, y patentizase con infinitos ejemplos, que los beneficios y las desgracias acaecían indistintamente a piadosos y a impíos, no por ello han desistido [los hombres] de su inveterado prejuicio: situar este hecho entre otras cosas desconocidas, cuya utilidad ignoraban (conservando así su presente e innato estado de ignorancia) les ha sido más fácil que destruir toda aquella estructura y planear otra nueva. Y de ahí que afirmasen como cosa cierta que los juicios de los dioses superaban con mucho la capacidad humana [cursivas mías].

Es verdad que en el apéndice, tal como se ve, la protesta de la experiencia no conduce a ningún lugar, o mejor, lleva a la profundización de la superstición con la aparición de la idea de que los fines divinos son insondables y de que, si apenas vemos alguna coherencia en el mundo, el problema es nuestro. Es eso lo que pasa. Sin embargo, a contramano de esa salida "más fácil" también surge una posibilidad de liberación; algo más difícil, sí, pero posible: "destruir toda aquella estructura y planear otra nueva". Nótese bien que la cuestión se sitúa entre lo más fácil y lo más difícil, no entre el posible y el imposible. Es necesario hacer algo, pero "qué es lo va a ser hecho" es otra historia.

¿Por qué es necesario hacer algo? Ante todo, observemos que la protesta de la experiencia, la cual exige hacer algo, no es una tesis filosófica o un despertar de la razón en medio del prejuicio; no: se trata de un hecho vulgar, cotidiano, que produce una desconfianza y una desesperanza casi triviales, bien humanas, desde el interior del propio prejuicio. Es la desesperación del hombre piadoso frente a una tragedia repentina que pone a prueba sus convicciones; es el descreimiento que va insinuándose en una persona cumplidora de sus deberes religiosos que, sin embargo, no encuentra satisfechas sus expectativas y experimenta una vida de infortunios y miserias. Los reveses de la fortuna, no raramente, ablandan los ánimos más porfiados, destrozando sin lástima todas las expectativas: todo se hace bien, pero todo sale mal. Dudar, en una situación como esa, es absolutamente humano.

Pues cuando nos sentimos abandonados y nuestras certezas de vida se debilitan, algo debe ser hecho. En el caso del apéndice, siendo 
el finalismo un sistema que explica lo real, lo que se hace es, por así decirlo, salvar los fenómenos utilizando la cláusula ad hoc de la insondabilidad de la voluntad divina. Pero la decepción también podría llevarnos hacia otra dirección: a la desconfianza en relación al código, a los valores que nos habían sido dados; en el límite, podría acarrear la destrucción de ese modo de vida finalista y — ¿por qué no?- la tentativa de forjar un nuevo modo de vida, indagando incluso por un bien verdadero diferente de aquel que se mostró un chasco. Esa vía no es seguida en el apéndice, pero surge incuestionablemente como una posibilidad.

En la secuencia del trecho del que tratamos, el apéndice afirma que, en razón del finalismo, la verdad escaparía para siempre a los hombres si la matemática no nos hubiese mostrado "otra norma de verdad". Por eso es común escuchar que el camino de la filosofía, en el spinozismo, sólo puede darse por la matemática. Sin embargo, es preciso no olvidar la continuación de la frase:

[...] y, además de la matemática, pueden también señalarse otras causas (cuya enumeración es aquí superflua) responsables de que los hombres se diesen cuenta (animadverterent) de estos vulgares prejuicios y se orientasen hacia el verdadero conocimiento de las cosas [cursivas mías].

Quizá sea imposible conferir precisión a ese genérico "otras causas", pero tampoco es ese nuestro propósito; queremos solamente incluir, entre esas "otras causas", la experiencia que abre el Tratado de la reforma del entendimiento.

La experiencia que enseña la vanidad y futilidad de las cosas, en el Tratado, es como la experiencia que contradice la fabrica o el sistema de la superstición, en el apéndice. Es difícil decir que la experiencia enseñe una norma de verdad (como la matemática), pero en los dos casos lo que importa es que ella nos fuerza a "darnos cuenta" de la incoherencia y tal vez de la falsedad del sistema en el que estamos inmersos y en el cual creemos; por un motivo muy sencillo: porque 
él no da cuenta, como debería hacerlo, de la propia experiencia cotidiana; o sea, la superstición falla, los impíos son felices, los piadosos son infaustos, los bienes llevan a la infelicidad, todo es vano y fútil. Ese desajuste perturba, hace dudar, sospechar y, en última instancia, sugiere una novedad, al menos la posibilidad de que se construya algo nuevo. Un estremecimiento (más o menos violento) de la estructura en la que nos encontramos presos (y la consecuente incertidumbre en cuanto al porvenir en su interior) acarrea un desprendimiento paulatino en relación a tal estructura, que en el Tratado de la reforma tiene el nombre de "vida común". Es desligándonos de la vida común y de sus cadenas que podemos pensar algo nuevo. En el apéndice, se hablaba de la estructura supersticiosa, se hablaba de "planear otra nueva"; en el inicio del Tratado encontramos reiteradamente la idea de establecer un nuevo modo de vida, una nueva vida que ocupe el lugar de la vida común — la fórmula novum institutum se repite cuatro veces sólo en los once primeros párrafos (una en el $\$ 3$, dos en el $\$ 6$, una en el $\$ 11$ ), hecho que demuestra cabalmente que la preocupación en instituir una nueva vida es la gran preocupación del inicio del filosofar.

Llegamos con eso al segundo momento de nuestro análisis. Hubo un estremecimiento en el sistema de la vida común; se descubrió, por las incoherencias de ese sistema, su convencionalidad: él no nos propone bienes y males que sean en sí verdaderos, sino bienes y males convencionales que sólo lo son en tanto nos afectan. Esta hendidura en el sistema genera desconfianza y abre un campo para el cambio, para lo nuevo. Abre una posibilidad, pero sólo eso no basta; en el Apéndice pasa lo mismo, y nada resulta. Es que es preciso, más allá de desconfiar de la vida que se lleva, decidirse a construir algo nuevo, una nueva vida.

¿¡Decisión!? ¿No estábamos nosotros, con Spinoza, en el terreno de la pura determinación? ¿Cómo conferir ahora alguna relevancia 
a tal noción que parece devolvernos al ilusorio libre arbitrio? Sí, es efectivamente una cuestión de decisión. Aunque éste sea uno de los puntos más fascinantes del Tratado de la reforma, no lo trataremos aquí en extensión; sólo haremos unas pocas advertencias que nos permitan pasar al punto que nos interesa.

El tema de la decisión en el spinozismo es frecuentemente visto como problemático, ya que se trata de un universo sin libre arbitrio, sin voluntad libre, y sin todo aquello que solemos asociar con la idea del decidirse. En la medida en que todo eso falta al spinozismo, a muchos les parece difícil pensar la decisión en esa filosofía. Por otro lado, si tratamos de comprender esta cuestión en Spinoza, no por aquello que le falta sino positivamente, podemos ir más lejos; en nuestro caso particular, el decidirse se caracteriza, en primer lugar, como tener que hacer algo. Hay un estremecimiento en la estructura en la que estamos inmersos, la del prejuicio o la de la vida común; somos coaccionados a hacer algo, pero la solución no es siempre la misma: podemos forjar los fines insondables de la divinidad o podemos —es el caso del Tratado de la reforma - ponernos a pensar, a filosofar. Las determinaciones, quizá, sean las mismas, las respuestas sin embargo pueden ser diferentes, aunque no menos determinadas. Es por eso que, punto que a nuestro ver es fundamental, una decisión puede ser objeto de ponderación y de análisis.

La toma de una decisión de hecho constituye un problema en un universo sin libre albedrío; pero justamente eso es lo relevante: es sólo en un mundo inmune al libre albedrío que ella es un problema real a ser pensado, un proceso determinado y pasible de análisis. De manera diferente a lo que ocurre cuando se imagina un sujeto libre que puede decidir cualquier cosa más allá de todas las determinaciones: en ese caso, la decisión no es problema simplemente porque asume aires de misterio; decidir por cualquier cosa será siempre, entonces, algo fácil. Pensemos en el Discurso del método, obra en muchos aspectos semejante al Tratado de la reforma. Descartes parece haber nacido 
para la filosofía y para ser Descartes; para él, el trayecto es fácil, y por eso el filósofo de la duda nunca duda realmente de su vocación ni pierde tiempo discutiendo su decisión de filosofar. En el Tratado de la reforma, al contrario, encontramos todas las dudas del mundo y las dudas de todo el mundo; incertidumbres, idas y vueltas, pasos atrás, percances en la realización de lo que se establece como objetivo. Por eso, también, el inicio del Tratado es tan rico; desde que el libre albedrío sale de escena, la decisión no se despega más del decidirse; es un proceso y, sobre todo, un proceso posible de análisis. Es exactamente lo que Spinoza nos propone, es decir, un análisis de su propio decidirse por la filosofía, de un proceso cuyo tiempo está bien marcado: él no decide de una manera pura y simple, no se da aquí la inmediatez del libre albedrío — “decidí finalmente”-, explicará. Sin que sea necesario detenernos en los detalles de ese autoanálisis, nos limitaremos a corroborar tal punto de vista señalando la presencia de un metadiscurso analítico que trabaja sobre hesitaciones y dudas reales, jamás dudas metódicas levantadas por una voluntad soberana: ${ }^{5}$ "después que la experiencia me había enseñado [...] como veía [...] me decidí finalmente" (\$1); "digo me decidi finalmente" (\$2); "con mi asidua meditación llegué a comprender que, si lograra entregarme seriamente a la deliberación" (\$7); "no en vano utilicé antes la expresión: si lograra entregarme seriamente a la deliberación" (\$10).

La decisión es un problema a ser tomado en serio. Decidir por lo más fácil, como los hombres del Apéndice, significa, frente a la necesidad de hacer algo, decidirse a no hacer nada y dar libre curso a las cosas, para el caso, a la ignorancia y la servidumbre nativas, a los prejuicios. Por el contrario, decidirse por lo más difícil, transformarse a sí mismo y a la vida, es una fuente de perturbaciones, un paso

5 Sobre la fórmula "duda real" aquí usada en oposición a "duda metódica”, ver (Spinoza, 1988: \$77). 
incluso violento: violencia contra la vida común que llevamos y por la cual somos llevados, violencia de algo que viene desde afuera y que nos obliga a pensar, meditar, deliberar; en cierto sentido, se trata de la violencia de ir contra nuestra situación natural, ya que "por naturaleza” somos propensos a seguir abrazados al prejuicio. Los términos de Spinoza en el Tratado de la reforma son fuertes al describir la situación de aquel que, decepcionado con los bienes comunes, busca otros; no nos permiten hacer caso omiso del dolor acarreado por el pensar en lo más difícil. Todo el ser del individuo y sus fuerzas se movilizan en una "única esperanza”: “conservar nuestro ser”, en la metáfora médica o, en el registro que nos es dado por la apertura del texto, esperanza de llegar a gozar de una "alegría suprema". ${ }^{6}$

La decisión por la alegría y por la búsqueda de la felicidad, la más difícil de las decisiones, es como el acto fundador del spinozismo. Y es eso lo que nos encamina hacia el tercer momento de la narrativa, cuando podremos ver esa decisión desplegarse en una creación de valores como bien y mal.

Una suprema alegría exige, ante todo, alegrarse. Una pregunta es entonces inevitable: ¿qué puede alegrarnos? Muchas e indefinidas cosas, entre las cuales no se incluirá, ciertamente, algo que presente el peligro de decepcionarnos y entristecernos. Ahora bien, el Tratado de la reforma se abre con el relato de una decepción. Desde siempre, la vida común nos inculca su valoración de las cosas: esto es un bien, aquello es un mal; esto trae felicidad, aquello trae desgracia. En ese sistema,

\footnotetext{
6 "Yo veía, en efecto, que me encontraba ante el máximo peligro (in summo versari periculo), por lo que me sentía forzado a buscar con todas mis fuerzas (summis viribus) un remedio, aunque fuera inseguro: lo mismo que el enfermo, que padece una enfermedad mortal, cuando prevé la muerte segura, si no se emplea un remedio, se ve forzado a buscarlo con todas sus fuerzas (summis viribus), aunque sea inseguro, precisamente porque en él reside su única esperanza” (\$7).
} 
los mayores bienes son el honor, las riquezas y el deseo sexual (libido); son ellos los que sostienen la promesa de alegría y felicidad. Pero, ¿la cumplen? No. Y es la decepción generada por tal incumplimiento la que, en el inicio de la obra, incita un proceso de cuestionamiento (todo es "vano y fútil") que perdura por algunos párrafos, modulados conforme se va afirmando el juicio del indagador: quizá esos bienes no sean tan seguros, quizá sean inciertos, quizá, por fin, sean con certeza inciertos, esto es, ciertamente decepcionantes o "males ciertos".?

Tal trayecto reevaluador, reiteremos, dura unos párrafos. Lo que en el ámbito de la narrativa spinoziana quiere decir: la reevaluación no se da una vez; hay una ponderación sobre la vida y el porvenir, ponderación de pros y de contras y una verdadera batalla interior. Todos me dicen que algo es un bien y todos buscan eso; estoy descontento, creo que eso no es un bien, e intento buscar otra cosa; pero, ¿y si yo estuviera equivocado (ya me equivoqué) y los otros estuvieran en lo cierto? Ponderaciones de ese tenor atraviesan el espíritu de Spinoza en el inicio del Tratado de la reforma; y tanto es así que no consigue siquiera dar libre ejecución a sus propias deliberaciones. Aunque "captara con toda claridad", nos confía el narrador, cuan decepcionantes son los bienes comunes, no podía "deponer toda avaricia, todo deseo sexual y toda gloria” ( $\$ 10)$. La batalla interna sólo tendrá término cuando se dé una completa reversión de los bienes comunes y de los valores a ellos vinculados, su reorganización en una nueva escala de valores, la cual permitirá al filósofo ponerlos en el lugar debido, no para abandonarlos definitivamente, sino para poder

\footnotetext{
${ }^{7}$ Tal análisis que estima el valor de los bienes comunes y del bien verdadero se desarrolla entre los $\$ \$ 2-7$ y tiene sus pasos bien marcados: "dejar una cosa cierta por otra todavía incierta" (\$2); "abandonaría un bien incierto por su propia naturaleza [...] por otro bien incierto, pero no por su naturaleza" (\$6); “dejaría males ciertos por un bien cierto" $(\$ 7)$.
} 
usufructuarlos sin decepción. Podemos ver en acción aquí la estrategia de la moderación: dar medida, reevaluar. Los que van a alterarse no son los bienes o las cosas, sino los valores conferidos a cada bien, a cada cosa y, principalmente, nuestra actitud respecto a los bienes y las cosas. La intervención de la idea de "verdadero bien" es la que operará ese cambio; es por su acción que se podrá determinar que "el conseguir riquezas, placer (libido) y gloria estorba, en la medida en que se los busca por sí mismos y no como medios para otras cosas"; y que, al revés, "si se buscan como medios, ya tienen medida (modum) y no estorban en absoluto, sino que, por el contrario, ayudarán mucho al fin por el que se buscan” (\$11).

El surgimiento del bien verdadero marca el reescalonamiento de los valores hasta entonces vigentes. Y una reorganización o reevaluación que asume un curioso acento finalista, ya que la noción de bien verdadero impondrá moderación y medida, estipulando a las cosas un lugar de medio que conduzca a un fin determinado. Los párrafos 12 y 13 constituyen el núcleo de esa operación y vale la pena citarlos por extenso, pues son la ponderación sobre el sentido de la estrategia ahí presente que constituirá el eje de nuestras conclusiones.

Sólo diré brevemente qué entiendo por verdadero bien y, a la vez, qué es el sumo bien. Para que se lo entienda correctamente, hay que señalar que el bien y el mal sólo se dicen en sentido relativo (respectivè), de forma que una y la misma cosa se puede decir buena y mala en sentidos distintos (secundùm diversos respectûs), lo mismo que lo perfecto y lo imperfecto. Nada, en efecto, considerado en su sola naturaleza, se dirá perfecto o imperfecto; sobre todo, una vez que comprendamos que todo cuanto sucede, se hace según el orden eterno y según las leyes fijas de la Naturaleza. Como, por otra parte, la debilidad humana no abarca con su pensamiento ese orden $y$, no obstante, el hombre concibe una naturaleza humana mucho más firme que la suya (aliquam humanam suâ multò firmiorem) y ve, mientras (interim), que nada impide que él la adquiera, se siente incitado a buscar los medios que le conduzcan a esa perfección. Todo aquello que puede ser medio para llegar a ella, se llama verdadero bien; y el sumo bien es alcan- 
zarla, de suerte que el hombre goce, con otros individuos, si es posible, de esa naturaleza.

En el inmediato inicio del párrafo siguiente, Spinoza afirmará: “éste es, pues, el fin al que tiendo" (\$14).

¿Cómo considerar, cómo entender ese movimiento spinoziano? Un paso desconcertante: se ha cedido al finalismo, combatido por todos los textos spinozianos, y su miríada de nociones derivadas: medio y fin, modelos, valores como bueno, malo, perfecto, imperfecto, etc. Y todo esto, notemos, en un trecho que se inicia justamente reafirmando la relatividad del bien y del mal, enseñanza de la experiencia que es crucial para el inicio del cuestionamiento filosófico. Ciertamente no se trata de un pecado de juventud, pues es el mismo paso presente en el prefacio de la Ética IV, en el cual se parte de una crítica a la idea de modelo, se retoma lo esencial de las críticas del apéndice a los fines y a los valores, y se termina estableciendo un "modelo de naturaleza humana" como fin y, de esa forma, rescatando las nociones de bueno y malo, perfecto e imperfecto (Spinoza, 1987:21-25). Busquemos comprender lo que pasa.

Spinoza reencuentra el finalismo. Pero no nos hallamos frente a un simple rescate, y esto es capital. Después de la enseńanza de la experiencia, la reconquista toma la forma de una manipulación consciente del finalismo, posible porque desde su apertura el Tratado nos coloca más allá del bien y del mal en sí, reales.

El volverse filósofo, reformarse y caminar hacia la libertad no implica parar de hablar de bien y de mal, de medios y de fines, sino forjar una nueva estructura, una nueva institución de vida que sustituya a la antigua estructura destruida. Se destruye construyendo, y tal construcción también se aplica necesariamente a los valores y a los fines. Aunque las nociones de bien, mal, etc., nada digan de lo real, sabemos que organizan lo real y, por consiguiente, la vida de los hombres, sabemos que organizan un mundo humano. Esto ocurre, según 
nos enseña el apéndice de la Ética, necesaria y determinadamente desde nuestra condición nativa; los hombres no eligen forjar valores y fines, pero lo hacen necesariamente. Ahora bien, sería bastante extraño que la felicidad tuviera que pasar por el olvido de todo eso que en los hombres es necesario — si fuera así, en los términos del Tratado político, tendríamos menos una ética que una sátira (I, $\$ 1)$ — El filósofo, y sobre todo aquel que se inicia en la filosofía, no puede olvidar lo que es humano en su nuevo modo de vida; lo que necesita es hacer un uso consciente de eso que es humano y necesariamente humano, o sea, una manipulación creativa y, especialmente, sin ilusiones.

El hallazgo fundamental del inicio del Tratado de la reforma es la convencionalidad de los bienes, de los valores que nos han sido propuestos. Se abre entonces un horizonte sin bien ni mal ni fines; donde todo sucede según un "orden eterno", según "leyes fijas", las cuales sin embargo no podemos alcanzar; se trata sólo de un mundo que acontece. ¿`Podemos quedarnos así? No. Al hallazgo de la convencionalidad o relatividad de los valores y de los fines, seguirá el reestablecimiento del bien, del mal, de los fines; serán ellos, es verdad, tan convencionales como antes, o sea, tampoco van a remitir a algo real, pero podrán volverse instrumentos valiosos, desde que se abra la posibilidad de una reorganización de la vida. ¿Por qué no proponer una nueva organización? Y dado que todo el problema del Tratado, desde su inicio, es la felicidad, ¿por qué no proponer una reorganización de las cosas y de la vida que favorezca al máximo nuestro camino hacia la felicidad, favoreciendo los encuentros alegres y el alejamiento de las tristezas?

Es de eso de lo que se trata: de poner orden en los afectos. Es lo que el modelo más firme de naturaleza humana y el "verdadero bien" realizan cuando surgen; suprimen las dudas, dan un nuevo contenido a los valores, reevalúan las cosas, establecen medios y fines, en una palabra: ordenan. La verdad del "verdadero bien" no está en corresponder a algo en lo real, sino en su poder ordenador; es la verdad de 
una eficacia para alegrar. El verdadero bien es una medida que deriva de un fin, un modelo de naturaleza humana que nos imponemos; la medida no es la de la verdad de las cosas, sino la del poder de producir alegría. Los términos del texto no nos permiten hacernos ilusiones. Poco antes de presentar el bien, se enfatiza que "bueno" y "malo" sólo se dicen "en sentido relativo" y que las cosas pueden ser buenas o malas "según varios puntos de vista"; no se niega esta relatividad ni siquiera en el momento de establecer un principio y un nuevo orden: precisamente, el hombre forja "una naturaleza humana mucho más firme que la suya", o sea, en relación a su naturaleza y no a las cosas en sí. El verdadero bien será, hablando con propiedad, una relación, un respectus: "todo aquello que puede ser medio para llegar" a aquella naturaleza más firme "se llama verdadero bien"; y podemos añadir, aunque Spinoza no lo haga: mal verdadero será lo que obstaculice nuestro avance rumbo a dicha naturaleza. Bien y mal son algo así como lugares, relaciones, espacios en ese nuevo orden que el iniciante se impone. Nuevo orden que, vale la pena repetir, podrá organizar los afectos de modo que el iniciante pueda alegrarse justamente al moderarlos. No es casual que Spinoza diga que, según esa nueva relación, incluso aquellos bienes decepcionantes como los honores y las riquezas puedan ser buscados sin daño; en efecto, "si se buscan como medios, ya tienen medida (modum)", quiere decir, estarán en el interior de un orden que los evaluará, los moderará, y no serán más buscados como "fines" en sí mismos (\$11).

Todo esto, señalemos, es realizado según un esquema finalista que no invoca ni siquiera algún principio racional. Ahora bien, podrían surgir varias dudas sobre si lo que se ha ganado no es, al fin de cuentas, muy poca cosa. Tales dudas no se sostienen, sin embargo, si sabemos apreciar lo sucedido; aunque parezca poco, aunque parezca que a pesar de caminar y caminar no hemos salido del mismo lugar, la impresión es falsa. El mayor de los acontecimientos —el de la liberación- empezó a despuntar, movido por la más difícil de las 
decisiones: la de ser libre. Tenemos todavía fines y valores; pero hubo un cambio en la esencia de tales fines y valores. Antes ellos nos eran simplemente dados y nos aprisionaban; ahora, nosotros los forjamos, los fabricamos, reconocemos su artificialidad y nos servimos de ella sin que ella nos capture. Antes servíamos a las cosas, ahora las cosas pueden servirnos. El resultado del pasaje puede ser poco perceptible, pero es un primer paso: no somos siervos, nos volvemos agentes (al menos en eso); no somos sólo determinados por todo y a todo, sino que en relación a algo somos nosotros los que nos determinamos; en relación a algunas cosas, a algunos aspectos de nuestra vida, podemos ahora decir que somos autónomos, o sea, que nos reglamos por nosotros mismos, al darnos el modo y la medida de nosotros y de nuestra vida. Y esto nos alegra. Debemos dar aquí todo el énfasis a la idea, presente en la quinta parte de la Ética, de un poder de ordenar (potestas ordinandi) las afecciones y, en consecuencia, los afectos, que somos capaces de ejercer mientras no estamos sometidos a ellos; ${ }^{8}$ en ese lapso, en alguna medida, somos libres. La libertad, allí, se vincula a lo que ya dijimos sobre la decisión: lo más difícil es decidir hacer algo nuevo, en vez de sólo dejar que las cosas sigan su curso, arrastrándonos de aquí para allá. Hacer algo es ser libre; una libertad que se expresa como el ejercicio de un poder o potencia de determinar y de autodeterminarse en vez de tan sólo padecer. Es un cambio de perspectiva que invierte la dirección de las determinaciones: pasamos de ser pacientes a ser, en algo, agentes; antes éramos sólo determinados por lo que venía desde afuera, ahora hay una determinación en sentido contrario, de adentro hacia afuera, que deberá consumarse en una vida nueva, un novum institutum, para recordar la fórmula del inicio del Tratado de la reforma.

\footnotetext{
8 "Mientras no nos dominen afectos contrarios a nuestra naturaleza, tenemos el poder de ordenar y concatenar las afecciones del cuerpo según un orden propio del entendimiento" (Spinoza, 1987:10).
} 
Regresemos a nuestra indagación inicial: ¡se crean valores en el spinozismo? Nos parece justa una respuesta afirmativa. Visto que nada es bueno o malo en sí, que la naturaleza no contiene fines ni modelos de cosa alguna, conferir algún sentido, cualquier sentido, a tales nociones será crear, instituir, colocar en uso convenciones, modos de pensar humanos que son valores. ¿Liviandad? De ninguna manera, pues no sólo se crean valores, sino que es necesario crearlos. El mundo humano produce valores y sin estos no puede asumir el estatuto de mundo humano; los hombres forman valores naturalmente, determinadamente desde su condición originaria; el problema, en ese caso, no serán los valores, sino cuáles serán esos valores y cuáles serán sus objetivos o fines; en cierto sentido, el valor de esos valores. Ninguna de las obras spinozianas deja persistir alguna ilusión sobre los valores absolutos; por el contrario, se afirma con énfasis que todo valor es relativo. Pero relativizar no implicará quedarse sin valores. Relativizar es, en primer lugar, deponer las ilusiones, conocer lo que es un valor y cuál es su lugar; segundo, forjar valores autónomamente o rescatar otros, renovándolos. Y es así como nos gustaría leer e interpretar el curioso movimiento spinoziano del inicio del Tratado de la reforma del entendimiento. Al trabajo crítico que nos da el conocimiento de nuestra condición y de las ilusiones de nuestra conciencia, es necesario que le siga un trabajo de creación de valores que contribuya para una nueva vida, nuevas formas (de preferencia alegres) de existir. Parece ser ésta toda la preocupación de aquel que se inicia en la filosofía en el Tratado; y queremos insistir en que no debemos ver allí un pecado de juventud: el filósofo maduro de la cuarta parte de la Ética no hará algo demasiado diferente, aunque el movimiento, en ese caso, nos conduzca por caminos más complejos que los del texto juvenil. ${ }^{9}$

\footnotetext{
${ }^{9}$ En relación a esto, vale la pena observar que no desconocemos las dificultades que la aproximación entre Spinoza y Nietzsche impone en el momento en el que
} 
Para concluir, toda la cuestión de nuestro texto puede resumirse así: ya que los valores son necesarios, tratemos nosotros de forjarlos en vistas de la alegría y del beneficio de la vida. Poder hacerlo quizá sea lo más difícil, pero necesitamos hacerlo. Si no lo hacemos, si nos restringimos a lo más fácil, el prejuicio, la tristeza, la superstición y sus custodios lo harán por nosotros.

\section{Bibliografía}

Nietzsche, Friedrich, 1985, Más allá del bien y del mal, Andrés Sánchez Pascual (trad.), Alianza, Madrid.

, 1986, “An Franz Overbeck (Postkarte) [Sils-Maria, 30. Juli 1881]”, en Sämtliche Briefe, vol. 6, Walter de Gruyter, Berlín / Nueva York.

, 1999, Sämtliche Werke. Kritische Studienausgabe, 15 vols., Giorgio Colli y Mazzino Montinari (eds.), Walter de Gruyter, Berlín / Nueva York.

Nietzsche en castellano, Horacio Potel (ed.), http://www.nietzscheana.com.ar/index.html. Consultado 27/xi/08.

Spinoza, Baruch, 1987, Ética, Vidal Peńa (trad.), Alianza, Madrid.

, 1972, Ópera, 4 vols., Carl Gebhardt (ed.), C. Winter, Heidelberg.

, 1988, Tratado de la reforma del entendimiento, Principios de filosofia de

Descartes, Pensamientos metafisicos, Atilano Domínguez (trad.), Alianza, Madrid.

Turco Liveri, Giuseppe, 2003, Nietzsche e Spinoza: Ricostruzione filosofico-storica di um incontro impossibile, Armando, Roma.

pasamos del plano del individuo al plano social. En efecto, el filósofo del Tratado, después de definir el "sumo bien", es claro: "a mi felicidad pertenece contribuir a que otros muchos entiendan lo mismo que yo, a fin de que su entendimiento y su deseo concuerden totalmente con mi entendimiento y con mi deseo [...] Es necesario, además, formar una sociedad, tal como cabría desear, a fin de que el mayor número posible de individuos alcance dicha naturaleza con la máxima facilidad y seguridad” (\$14). Nos parece que ese aspecto social, si podemos llamarlo así, de la conversión filosófica spinoziana (que se revelará con toda su fuerza en las obras de madurez) es ajeno a la filosofía nietzscheana. 